\title{
Factors Associated with Intestinal Atresia and Its Complications
}

\author{
Hayder Neamah Hassan ${ }^{1}$
}

\author{
${ }^{1}$ College of Medicine, University of Kufa, Iraq \\ ${ }^{*}$ Corresponding author. Email: haidern.alkhayat@uokufa.edu.iq
}

\begin{abstract}
Intestinal atresia occurs as 1.3 to 3.5 cases per 10,000 live births, and the understanding of the factors associated with occurrence and complications of intestinal atresia. The current study's goal is to evaluate the various forms of intestinal atresia, and factors associated with intestinal atresia and its complications. Thirty-two infants diagnosed with intestinal atresia were included in the current study. The study was conducted at Al-Zahra Teaching Hospital in Al-Najaf city, in Iraq, during the period between October 2018 to March 2021. The results of the current study show most of neonates have gestational age of 36 weeks $(37.5 \%)$, those with birth weight less than $2.5 \mathrm{Kg}(75 \%)$, those age at presentation between (4-5) days (50\%), those with hospital stay (4-7) days (46.9\%), male patients (59.4\%), those with no associated anomalies $(65.6 \%)$, those with no complications $(68.8 \%)$, type is IIIa $(28.1 \%)$, and finally only $(18.8 \%)$ of them had died. The results of the current study show the significant relationship between type of intestinal atresia with complications ( $p$ value $=0.02$ ). It was concluded that the most common type of jenunoileal atresia is IIIa. There is an association between complications of intestinal atresia and each of: birth weight, gestational age and hospital stay. It was also concluded relationship between type of intestinal atresia and complications.
\end{abstract}

Keywords: intestinal atresia, duodenal, jejunoileal, associated anomalies.

\section{INTRODUCTION}

A congenital defect in a hollow viscus that fully closes the lumen is known as ductal atresia. One of the most common causes of bowel blockage in new-borns is intestinal atresia, which may appear at any location in the digestive system. The duodenum is a big component in one-half of the cases [1].

The reported incidence of intestinal atresia ranges from 1.3 to 3.5 per 10,000 live births, of which approximately 20 percent are associated with a chromosomal anomaly. The incidence and accompanying abnormalities vary depending on the anatomical site: Duodenal atresia affects around 1 in every 10,000 new-borns and accounts for up to $60 \%$ of all small intestinal atresias. Approximately 30 percent of infants with duodenal atresia have a chromosomal anomaly, primarily Down syndrome [2] .

In recent decades, intensive care, surgical treatments, and artificial feeding have all improved the survival rate of most vulnerable infants with congenital Jejunoileal Atresia (JIA).The selection of surgical options aims to ensure that the longest length of the intestine is spared even if it must be passed via numerous anastomoses [2], and duodenal atresia (DA) is a congenital intestinal blockage that affects one in every 5000-10,000 live births and affects males more often than girls [3]. Additionally, more than $50 \%$ of babies with DA are found to have an underlying congenital abnormality, such as (vertebral defects, anal atresia, cardiac defects, tracheo-esophageal fistula, renal anomalies, and limb abnormalities) which stand for (VACTERL). Gastrointestinal abnormalities are most frequently seen in the gastrointestinal tract. If in this instance, the most frequently related abnormalities are annular pancreas, intestinal malrotation, and intestinal atresia and/or stenosis, the anomaly that most commonly appears is intestinal atresia and/or stenosis [4] .

It's really well-known that a missing postoperative anastomosis or intestinal web may induce postoperative bowel blockage, an increased hospital stay, and more time on parenteral nutrition because of a delay in starting feeds. This section is occupied by individuals who advocate laparoscopic surgery and others who favor an open procedure [5]. An solitary occurrence of a condition is called a singleton. They may be combined 
with other congenital abnormalities, or may be associated with a chromosomal anomaly, namely trisomy 21 . According to studies, approximately one-third of individuals identified with duodenal atresia prenatally had Down syndrome, and 3-5\% of those with trisomy 21 have duodenal atresia [6]. The study's main goal is to examine the many kinds of intestinal atresia, as well as related variables.

\section{PATIENTS \& METHODS}

Thirty-two infants diagnosed with intestinal atresia were included in the current study. The study was conducted at Al-Zahra Teaching Hospital in Al-Najaf city, in Iraq, during the period between October 2018 to March 2021. The following data have been collected: ((Type of intestinal atresia, Gestational Age, Age at presentation, Birth Weight, Hospital Stay, Gender, Associated Anomalies, Complications)). Statistical Table 1. General characteristics of the study sample analysis was done by SPSS program (version 25) including both descriptive (frequency and percentage) and inferential statistics (Chi square).

\section{RESULTS}

Table (1) demonstrates the general features of the research sample, it explain the highest percentage of the children subgroup are: those with gestational age of 36 weeks $(37.5 \%)$, those with birth weight less than $2.5 \mathrm{Kg}$ (75\%), those age at presentation between (4-5) days $(50 \%)$, those with hospital stay (4-7) days (46.9\%), male patients $(59.4 \%)$, those with no associated anomalies $(65.6 \%)$, those with no complications $(68.8 \%)$, and finally only $(18.8 \%)$ of them had died .

Table (2) shows the descriptive statistics of the types of intestinal atresia, it shows that the most prevalent type is IIIa $(28.1 \%)$.

\begin{tabular}{|c|c|c|c|}
\hline Items & Sub-groups & Freq. $($ Total $=32)$ & Percent. \\
\hline \multirow{4}{*}{ Gestational Age / Weeks } & 35 & 8 & 25.0 \\
\hline & 36 & 12 & 37.5 \\
\hline & 37 & 7 & 21.9 \\
\hline & 38 & 5 & 15.6 \\
\hline \multicolumn{4}{|c|}{ Mean \pm SD (Range) : 36.28 $\pm 1.02(35-38)$} \\
\hline \multirow{2}{*}{ Birth Weight / Kg } & $<2.5$ & 24 & 75 \\
\hline & $\geq 2.5$ & 8 & 25 \\
\hline \multicolumn{4}{|c|}{ Mean \pm SD (Range) : $2.22 \pm 0.42(1.6-3.1)$} \\
\hline \multirow{3}{*}{ Age at presentation } & $2-3$ & 12 & 37.5 \\
\hline & $4-5$ & 16 & 50 \\
\hline & $6-7$ & 4 & 12.5 \\
\hline \multicolumn{4}{|c|}{ Mean \pm SD (Range) : 4.03 $\pm 1.47(2-8)$} \\
\hline \multirow{3}{*}{ Hospital Stay/ days } & $0-3$ & 6 & 18.8 \\
\hline & $4-7$ & 15 & 46.9 \\
\hline & $8-11$ & 11 & 34.4 \\
\hline \multicolumn{4}{|c|}{ Mean \pm SD (Range) : 4.03 $\pm 1.47(2-8)$} \\
\hline \multirow{2}{*}{ Gender } & Male & 19 & 59.4 \\
\hline & Female & 13 & 40.6 \\
\hline \multirow{2}{*}{ Associated Anomalies } & Yes & 21 & 65.6 \\
\hline & No & 11 & 34.4 \\
\hline \multirow{3}{*}{ Complications } & Death & 6 & 18.8 \\
\hline & Present & 4 & 12.5 \\
\hline & Absent & 22 & 68.8 \\
\hline
\end{tabular}


Table 2. Descriptive statistics of the types of intestinal atresia

\begin{tabular}{|c|c|c|c|}
\hline \multicolumn{2}{|c|}{ Items } & Frequency (Total = 32) & $\%$ \\
\hline \multicolumn{2}{|c|}{ Duodenal } & 6 & 18.8 \\
\hline \multirow{5}{*}{ Jejuno-lleal Atresia } & I & 8 & 25.0 \\
\hline & II & 4 & 12.5 \\
\hline & IIIa & 9 & 28.1 \\
\hline & $\mathrm{Illb}$ & 1 & 3.1 \\
\hline & IV & 4 & 12.5 \\
\hline
\end{tabular}

neonates characteristics, it shows that there is a

Table (3) is about relationship between neonates characteristics and the type of intestinal atresia, it shows that there is no significant relationship except with Complications in which there was significant relationship ( $\mathrm{p}$ value $=0.02$ ). Table $(4)$ reveals the values of Chi square values for the relationships between different

Table 3. Chi square values for the relationships between different neonates characteristics

\begin{tabular}{|c|r|r|r|r|r|r|}
\hline Items & Birth Weight Gestational Age & $\begin{array}{c}\text { Age at } \\
\text { presentation }\end{array}$ & Hospital Stay & Gender & $\begin{array}{c}\text { Associated } \\
\text { Anomalies }\end{array}$ \\
\hline Gestational Age & $25.23^{*}$ & & & & & \\
\hline Age at presentation & 2.10 & 2.21 & & & & \\
\hline Hospital Stay & 3.12 & 1.32 & 1.56 & & & \\
\hline Gender & 2.36 & 3.27 & 2.03 & 0.33 & & \\
\hline Associated Anomalies & 1.25 & 1.15 & 0.98 & 0.26 & 0.65 & \\
\hline Complications & $9.54^{*}$ & $8.23^{*}$ & 0.88 & $11.49^{*}$ & 0.94 & 1.36 \\
\hline
\end{tabular}

Table 4. Relationships between neonates characteristics and type of intestinal atresia

\begin{tabular}{|c|c|c|c|}
\hline Items & $\mathrm{df}$ & Chi Square & 0.33 \\
\hline Gestational Age & 15 & 1.86 & 0.51 \\
\hline Birth Weight & 5 & 1.41 & 0.26 \\
\hline Age at presentation & 10 & 2.21 & 0.49 \\
\hline Hospital Stay & 10 & 1.32 & 0.65 \\
\hline Gender & 5 & 3.27 & 0.94 \\
\hline Associated Anomalies & 5 & 1.15 & 0.02 \\
\hline Complications & 10 & 22.02 & \\
\hline
\end{tabular}

\section{DISCUSSION}

The clinical characteristics of the studied neonates come in accordance to a previous study that indicated the male constitutes about $(58.1 \%)$ of the total neonates with JIA, the average gestational age was 36 weeks. (range 27-41) and mean birth weight (BW) was $2.644 \mathrm{~g}$ (range 730 - 4.120, SD 785) [7]. Regarding the type of, our study may agree with Stollman et al. (2009) who found that the distribution of the types of jejunoileal atresia was as follows: $16 \%, 21 \%, 24 \%, 10 \%$, and $22 \%$ for : type I , type II, type IIIa , type IIIb, and type IV respectively [8].

Duodenal atresia mortality rates have decreased dramatically during the last three decades, averaging $2 \%$ to $5 \%$. The procedure is not directly linked to mortality rates, but other organ abnormalities such as complicated congenital heart problems are. Survival rates are improving because to improved NICU care, nutritional 
assistance, and paediatric anaesthetic. Long-term survival of most babies with duodenal atresia (more than $80 \%$ ) is now the norm. The use of endoscopy to remove the duodenal web is likely to be the most contentious issue in the future. This method is still being tested. Another point of contention is when the patient should be fed following surgery [9].

The median birth weight was considerably lower (median 2,550 vs. 2,980 g) There were no changes in gender, preterm, small for gestational age, birth weight, cardiac abnormality, type of atresia, primary anastomosis, or complication grade $\geqslant 2$ in the group with a longer hospital stay $(\mathrm{p}=0.04)$. or residual bowel length. [10[ . Regarding complications, the results of the current study matches other studies which found complication rates between 18 to $46 \%$ [11-12].

The difference in complication rate may be explained by the number of various problems examined, and the present research included central line issues, which had not previously been included in investigations. As a consequence, central line issues including infection, thrombosis, and dysfunction were the most common in this study. Infants with any central line issue took considerably longer to finish enteral feeding and were hospitalized for significantly longer periods of time. When a central line malfunction occurs, time with parenteral nutrition is often prolonged, and there is often a need for a surgical intervention under general anesthesia, which temporarily disrupts and prolongs time to complete enteral feeding, thus extending hospital stay. The causation may, however, be inverted; the longer the babies remain on parenteral nourishment or in the hospital, the higher the chance of having a central line problem [13]. Low birth weight has been linked to an increased risk of death in JIA patients. Previous research has linked low birth weight to a more difficult postoperative period [10].

\section{CONCLUSION}

It was concluded that the most common type of jenunoileal atresia is IIIa. There is an association between complications of intestinal atresia and each of: birth weight, gestational age and hospital stay. It was also concluded relationship between type of intestinal atresia and complications

\section{REFERENCES}

[1] G.S. Bethell, A.M. Long, M. Knight, Congenital duodenal obstruction in the UK: a population-based study. Arch Dis Child Fetal Neonatal Ed, 2020; 105, $\mathrm{P}: 178$.

[2] S. Prachuapthunyachart, S. Merani, M. Cloonan. Immune function and infectious complications in children with jejunoileal atresia. J Pediatr Surg, 2021; 56, P : 454.
[3] M. Lima, N. Di Salvo, C. Cordola, S. D'Antonio, M. Libri, M. Maffi. Laparoscopy-Assisted Versus Open Surgery in Treating Intestinal Atresia: Single Center Experience. J Invest Surg., 2020, 8, PP: 1-6.

[4] J. K. Morris, A. L. Springett, R. Greenlees, M. Loane, M. C. Addor, L. Arriola, I. Barisic, J.E.H. Bergman, Csaky-Szunyogh M, Dias C, Draper ES, E. Garne, M. Gatt, B. Khoshnood, K. Klungsoyr, C. Lynch, R . Trends in congenital anomalies in Europe from 1980 to 2012. PLoS One., 2018;13(4), P : e0194986.

[5] J. M. Latzman, T. L. Levin, S. M. Nafday Duodenal atresia: not always a double bubble. Pediatr Radiol. 2014, 44(8), PP : 1031-4.

[6] J.C. Bishop, B. McCormick, Johnson C.T. The Double Bubble Sign: Duodenal Atresia and Associated Genetic Etiologies. Fetal Diagn Ther. 2020, 47(2), PP: 98-103.

[7] C. Calisti, Olivieri, R. Coletta, V. Briganti, L. Oriolo, G. Giannino. Jejunoileal Atresia: Factors Affecting the Outcome and Long-term Sequelae. J Clin Neonatol. 2012;1(1), PP:38-41.

[8] T. H. Stollman, I. de Blaauw, M. H. Wijnen, F. H. van der Staak, P.N. Rieu, J. M. Draaisma. Decreased mortality but increased morbidity in neonates with jejunoileal atresia; a study of 114 cases over a 34year period. J Pediatr Surg. 2009, 44 (1), PP:217-21.

[9] V.Hemming, \& J. Rankin. Small intestinal atresia in a defined population: occurrence, prenatal diagnosis and survival. Prenatal diagnosis, 2007, 27(13), PP:1205-1211.

[10] C. Jarkman, M. Salö. Predictive Factors for Postoperative Outcome in Children with Jejunoileal Atresia. Surg J (N Y). 2019;5(4), PP: e131-e136.

[11] A. Calisti, C. Olivieri, R. Coletta, V. Briganti, L. Oriolo, G. Giannino. Jejunoileal atresia: Factors affecting the outcome and long-term sequelae. J Clin Neonatol., 2012 1(01), PP : 38-41.

[12] S. Burjonrappa, E. Crete, S. Bouchard Comparative outcomes in intestinal atresia: a clinical outcome and pathophysiology analysis. Pediatr Surg Int. 2011, 27(4), PP:437-442.

[13] J. Gonzalez-Hernandez, P. Prajapati, G. Ogola, N. Channabasappa, B. Drews, H. G. Piper. Predicting time to full enteral nutrition in children after significant bowel resection. J Pediatr Surg. 2017, 52(05), PP:764-767. 